\title{
Optimization of Building Layouts to Increase Wind Turbine Power Output in the Built Environment Assumed to Be Installed at Fukushima City and Tsu City in Japan
}

\author{
Akira Nishimura1 ${ }^{*}$, Masanobu Kakita1, Junsuke Murata1, Toshitake Ando1, \\ Yasunari Kamada', Masafumi Hirota', Mohan Lal Kolhe ${ }^{2}$ \\ ${ }^{1}$ Division of Mechanical Engineering, Graduate School of Engineering, Mie University, Tsu, Japan \\ ${ }^{2}$ Faculty of Engineering and Science, University of Agder, Grimstad, Norway

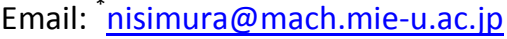

Received 3 August 2015; accepted 4 September 2015; published 7 September 2015

Copyright (C) 2015 by authors and Scientific Research Publishing Inc.

This work is licensed under the Creative Commons Attribution International License (CC BY). http://creativecommons.org/licenses/by/4.0/

c.) (i) Open Access

\section{Abstract}

It is very important to consider proper intelligent integration and locations of renewable energy sources into the built environment for developing smart cities. Wind speed distribution study in the built environment is very essential for analyzing the wind turbine performance located in the built environment. In this work, the building layout like nozzle is proposed and the objective is to optimize the building layout for increasing electrical energy output of wind turbine, assumed to be installed in actual cities of Japan. The wind speed distribution across buildings is numerically simulated by using CFD-ACE+. Wind turbine power output is estimated using the power curve of a real commercial wind turbine and wind speed distribution is simulated using CFD software. The meteorological data of Fukushima city and Tsu city of Japan are utilized for evaluating the wind speed distribution profile across the building and for finding the electrical energy output from wind turbine. The proposed building models, which have the angle between two buildings like nozzle of $90^{\circ}, 135^{\circ}$ and $180^{\circ}$, can provide the wind acceleration at the back of buildings for the wind blowing from the main wind direction and the angle of $135^{\circ}$ is optimum building layout. In the case of installing the proposed building model in Fukushima city and Tsu city, the wind energy output in winter season is higher while that in summer season is lower irrespective of the buildings' angle. The interaction between the change in frequency distribution of wind speed and direction throughout the year and the location of open tip of building model decides the power generation characteristics of the proposed building model.

\footnotetext{
"Corresponding author.

How to cite this paper: Nishimura, A., Kakita, M., Murata, J., Ando, T., Kamada, Y., Hirota, M. and Kolhe, M.L. (2015) Optimization of Building Layouts to Increase Wind Turbine Power Output in the Built Environment Assumed to Be Installed at Fukushima City and Tsu City in Japan. Smart Grid and Renewable Energy, 6, 279-292.
} 


\section{Keywords}

\section{Built Environment Wind Turbine, Built Environment Wind Speed Distribution, Building Layouts for Built Environment Wind Turbine, Smart City}

\section{Introduction}

For city planning, it is very important to propose the building model for integrating and locating environment friendly energy systems. It is effective to construct a smart city, consisting proposed buildings orientations for not only meeting the energy demand but also decreasing the amount of $\mathrm{CO}_{2}$ emitted by power generation. In developing environment friendly smart cities, it is needed to analyze the intelligent integration with proper location of intermittent renewable energy sources in the built environment [1]-[3]. This study is proposing the built environment wind turbine locations as well as proper building layouts for utilizing the wind speed distribution effectively within the built environment. The city consists of many buildings and the buildings are thought to be an obstacle for natural wind flow. However, this wind distribution can be utilized for power generation of wind turbine if the wind blowing through building is managed through building orientations and layouts. In this study, horizontal axis wind turbine is considered for utilizing the effective wind speed distribution due to building layouts.

The wind speed profiles on the tall building rooftops are presented in the reference [4] for analyzing the usage of roof wind energy, but it has not considered the wind speed distribution due to the building topologies of the city. Numerical simulation on wind flow around building has been carried out by turbulent models such as standard $k-\varepsilon$, LES and DNS and they have been reported in [5]-[11]. In addition, the wind tunnel experiments on wind flow around building have been also reported in [12]-[15]. Although these reports have investigated the wind speed profile/distribution around various building models, there is no report considering building size dimension and layout in order to utilize the wind speed distribution around building for power generation of wind turbine [5]-[15]. To realize the wind energy utilization in the built environment, it is important to conduct a feasibility study on wind turbine power generation performance under the actual wind condition as well as considering impact of building layouts and wind turbine location.

It is observed through literature survey that no study has been reported yet for analyzing built environment wind turbine power output due to wind speed distribution considering building layouts [16]-[25]. In our previous studies [1] [2], the assessment of wind turbine power output in the built environment has been presented. It has also discussed the wind speed distribution in the built environment. The wind speed acceleration in the built environment has been confirmed when the building layout, like nozzle, is considered [2]. Using the wind speed data base of the Japan Meteorological Agency [26], the annual power generation characteristics of wind turbine have been investigated in the case of installing the building model in Tsu city, Japan. However, only one building layout has been investigated in it [2]. Therefore, the impact of building topologies/layouts has not been investigated on wind speed profiles and also on their utilization for wind turbine in the urban area/built environment [2]. It is important to optimize the building layout using actual meteorological data for increasing power output of built environment located wind turbine under the realistic condition.

In the present paper, the objective is to optimize building layout for increasing electrical energy output from wind turbine assumed to be installed in the actual city in Japan. In this work, the angle between two buildings, like nozzle $(\alpha)$, is changed by $90^{\circ}, 135^{\circ}$ and $180^{\circ}$. According to our previous study [2], the wind speed acceleration in the built environment is obtained at $\alpha=90^{\circ}$. In the present paper, the angle wider than $90^{\circ}$ is investigated, since it is predicted that the larger amount of wind from many wind directions can inflow into the intervening space within the two buildings like nozzle. Figure 1 shows the building model with $\alpha=135^{\circ}$. The wind speed distribution across the buildings is developed/simulated through a CFD (Computational Fluid Dynamics) software. The power output from wind turbine is estimated using the power curve of a real commercial wind turbine and the wind speed distribution around buildings. The present paper focuses on analysis of the wind speed distribution around the building at different building angles (i.e. nozzle angles) and to investigate the wind turbine power generation performance. Also, this work presents the change in wind speed profile and wind turbine electrical energy output with reference to the various building topologies in a smart city planning. 


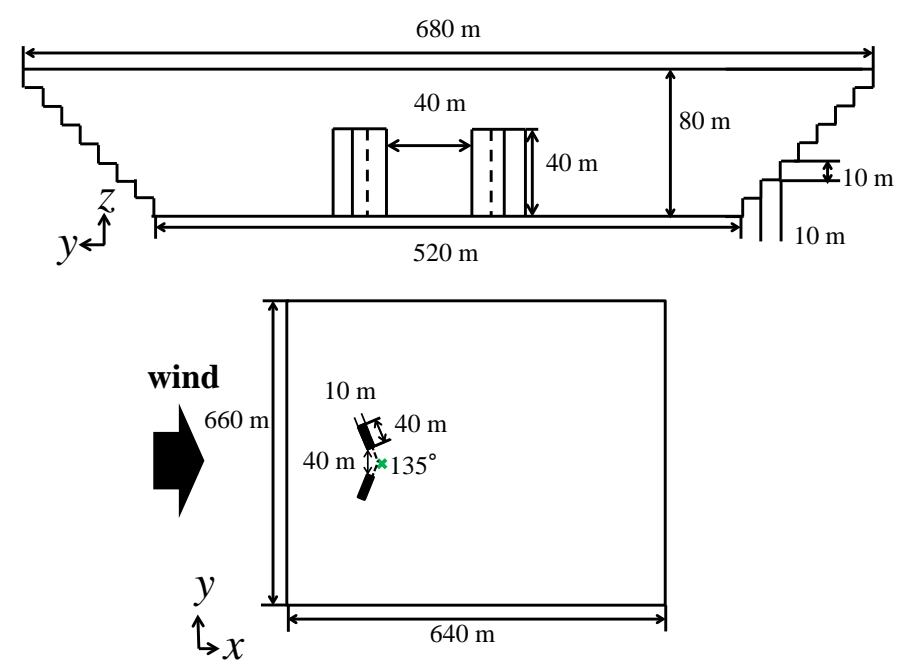

Figure 1. Simulation model for wind power generation.

The wind speed data base of the Japan Meteorological Agency [26] is used in this work. The meteorological data are utilized for evaluating the wind speed profile across the building and for finding the electrical energy output of wind turbine. The data for Fukushima city (located at east longitude of $140^{\circ}$ and 28 arc-minute, north latitude of $37^{\circ}$ and 45 arc-minute) and Tsu city (located at east longitude of $136^{\circ}$ and 30 arc-minute, north latitude of $34^{\circ}$ and 43 arc-minute) in Japan are used for the feasibility assessment of the proposed building model/layout. Fukushima city which is located in the northeast region in Japan is still suffering from the damage of the big earthquake and nuclear power plant accident occurred in 2011. This study believes that a smart city is suitable for the reconstructing of the Fukushima city. The Tsu city which is located in the center region in Japan is far from the Fukushima city. This study picks up these cities as representative middle size city in the Japan.

Two buildings are configured/arrayed as a nozzle (Figure 1) and considered building size is $10 \mathrm{~m}$ width, $40 \mathrm{~m}$ length and $40 \mathrm{~m}$ height. The representative length of this model $L$, which is a hydraulic diameter of horizontal cross area, is $16 \mathrm{~m}$. The distance between two buildings is $40 \mathrm{~m}$, which is optimized in our previous study [1]. In city planning, there will be several buildings, but this work considers only two buildings. In future work, multi buildings layouts will be considered for wind speed distribution in the downstream. Also it will consider the ground surface elevation/topologies etc. The results of this study may be useful for city planner for finding the proper locations of buildings for effective utilization of wind energy resources in the built environment.

\section{Analysis of Procedure of Building Model}

In this work, the wind speed distribution across the buildings is developed/simulated through the commercial CFD software CFD-ACE+ (ESI Japan, Ltd.). The previous works [1] [2] have also used this CFD-ACE+ for assessment of wind turbine power output in the built environment. The wind speed distribution model and simulation procedure, which have been used in this study, have been already presented in the Section 2 of our previous study [1]. In the present paper, the wind speed estimation procedure, which includes the several same steps as the previous study [2], is explained as follows:

The wind at the area at the back of buildings is thought to be available for power generation by wind turbine, since the wind speed would be accelerated by blowing through the buildings. Three points at the back of building which are apart from the building by 20,30 and $40 \mathrm{~m}(x / L=1.25,1.875,2.50)$ is assumed as the installation point of wind turbine. The wind speed for calculating the power generated by wind turbine is obtained on 1049 points located in the area where the rotor of wind turbine rotates, that is, the swept rotor area. The wind speed at each point on the swept rotor area is the averaged speed in the local area of $0.5 \mathrm{~m} \times 0.5 \mathrm{~m}$. By considering the wind speed distribution of this local wind speed, the wind energy can be calculated. Root mean cube wind speed to $x$ axis direction is estimated by using the following equation:

$$
U_{r m c}=\left(\frac{2 Q_{x}}{N \rho A}\right)^{1 / 3}
$$


where $U_{r m c}$ is the root mean cube wind speed to $x$ axis direction, $Q_{x}$ is the summation of wind energy to $x$ axis direction on each point for calculating wind speed distribution, $N$ is the points for calculating wind speed distribution in the swept rotor area $A$ (= 1049 points), $\rho$ is the density of wind, $A$ is the swept rotor area. Wind energy at each point on the swept rotor area is calculated by the following equation:

$$
Q_{x}=\sum_{i=1}^{1049} Q_{x, i}=\sum_{i=1}^{1049}\left(\frac{1}{2} \rho A_{i} U_{i}^{3}\right)
$$

where $Q_{x, i}$ is the wind energy to $x$ axis direction at each point, $A_{i}$ is the area of each point which is equal to $0.5 \mathrm{~m} \times$ $0.5 \mathrm{~m}, U_{i}$ is the wind speed to $x$ axis direction at each point for calculating wind energy. $V_{r m c}$ which is the root mean cube wind speed to $y$ axis direction is estimated by the same calculation way of $U_{r m c}$. The average root mean square wind speed to horizontal surface of the swept rotor area $U_{h, \text { ave }}$ is calculated by the following equation:

$$
U_{h, a v e}=\sqrt{U_{r m c}^{2}+V_{r m c}^{2}}
$$

Here, the wind speed and wind energy to $z$ axis direction are ignored since the rotor of wind turbine can't move toward $z$ axis direction and wind energy to $z$ axis direction can't be utilized.

Building design procedure has been explained in reference [1]. Also the other parameters, e.g., wind turbine specifications, power curve for estimation of wind power output has been reported in reference [1] and they are also used in the present paper. Table 1 lists the specification of wind turbine. In this study, the real commercial wind turbine is adopted for estimating the power generated by wind speed distribution. AEOLOS wind turbine of $50 \mathrm{~kW}$ class [27] is adopted in this study. The hub height and rotor diameter of this wind turbine is $30 \mathrm{~m}$ and $9 \mathrm{~m}$, respectively, resulting that the height of building of $40 \mathrm{~m}$ is almost same as the axis height of wind turbine. Table 2 lists the simulation condition in this study. Numerical simulation has been conducted under steady state

Table 1. Specification of wind turbine.

\begin{tabular}{ccc}
\hline Characteristics & Figure \\
Rated power $(\mathrm{kW})$ & 50 \\
Start wind speed $(\mathrm{m} / \mathrm{s})$ & 3 \\
Cut-in wind speed $(\mathrm{m} / \mathrm{s})$ & 3 \\
Cut-out wind speed $(\mathrm{m} / \mathrm{s})$ & 18 \\
Rotor diameter $(\mathrm{m})$ & 60 \\
Rotor speed $(\mathrm{rpm})$ & 30 \\
Hub height $(\mathrm{m})$ & 30 \\
\hline
\end{tabular}

Table 2. Simulation condition of this study.

\begin{tabular}{cc}
\hline Condition & Configuration \\
\hline Density of wind at inlet $\left(\mathrm{kg} / \mathrm{m}^{3}\right)$ & 1.166 \\
Temperature of wind at inlet $(\mathrm{K})$ & 293 \\
Pressure of wind at inlet $(\mathrm{MPa})$ & 0.10 \\
Kinetic viscosity of wind $\left(\mathrm{m}^{2} / \mathrm{s}\right)$ & $1.56 \times 10^{-5}$ \\
Wind speed at inlet $(\mathrm{m} / \mathrm{s})$ & $U=U_{0} \times(\mathrm{z} / 30)^{0.25}\left(U_{0}=3.00-12.00\right)$ \\
Slip on side wall of building $(\mathrm{m} / \mathrm{s})$ & $V=(0.41 \times|l|)^{0.25} U$ \\
Turbulent flow model & $\mathrm{RNG} k-\varepsilon$ model \\
Turbulent energy $\left(\mathrm{m}^{2} / \mathrm{s}^{2}\right)$ & 0.025 \\
Dissipation rate $\left(\mathrm{m}^{2} / \mathrm{s}^{2}\right)$ & $\left(1.58 \times 10^{-3}\right) / z$ \\
Calculation number $(-)$ & 10,000 \\
Residue of each parameter $(-)$ & $<1.0 \times 10^{-5}$ \\
Calculation state & Steady state \\
\hline
\end{tabular}


by RNG $k-\varepsilon$ model. Calculation number is set 10,000 times. This calculation number should be appropriate since the residue of each parameter under each numerical simulation condition keeps a stable small value after 500 times calculation. Wind speed at inlet of the model is set by the following equation:

$$
U=U_{0} \times\left(\frac{z}{30}\right)^{0.25}
$$

where $U$ is the wind speed in $x$ direction, $U_{0}$ is the initial wind speed at $z=30 \mathrm{~m}$, which is changed from $3.0 \mathrm{~m} / \mathrm{s}$ to $12.0 \mathrm{~m} / \mathrm{s}, z$ is height. $U_{0}=10.0 \mathrm{~m} / \mathrm{s}$ the rated wind speed of AEOLOS wind turbine of $50 \mathrm{~kW}$ class [27]. It is assumed that $U$ equals to $U_{0}$ at $z=30 \mathrm{~m}$ which is the hub height of wind turbine when the wind reaches to the building.

In this work, wind speed data for Fukushima city and Tsu city are used from the Japan Meteorological Agency [26]. The wind speed data of five years (from 2010 to 2014) are used. Since the wind speed observation height by the Japan Meteorological Agency [26] is lower compared to the hub height of wind turbine, e.g., $2.6 \mathrm{~m}$ in the case of Fukushima city, the following correction formula [21] is used to derive the $U_{0}$ :

$$
\frac{U_{o}}{U_{0}}=\left(\frac{z_{o}}{30}\right)^{a}
$$

where $U_{o}$ is the wind speed at observation height for each city in the data base, $z_{o}$ is the wind speed observation height for each city in the data base, $a$ is the wind shear coefficient. In this study, $\alpha=0.25$, corresponding to the country area with many trees, is adopted; since Fukushima city and Tsu city have large country area as well as urban area.

In this study, the buildings are located as nozzle, therefore the wind inflow direction is important for obtaining the wind blowing through the buildings. The layouts of the buildings are decided based on the wind speed direction. The wind speed directions and buildings with $\alpha=135^{\circ}$ are given in Figure 2. In this case, if the main wind direction is North $(\mathrm{N})$, the wind from West-North-West (WNW), North-West (NW), North-North-West (NNW), North-North-East (NNE), North-East (NE) and East-North-East (ENE) including $\mathrm{N}$ can be utilized for blowing the wind among the buildings through nozzle. It is assumed that the wind blowing from the directions except for the above described wind directions can't be utilized for power generation of wind turbine. If the buildings with $\alpha=90^{\circ}$ are located, the wind from NW, NNW, NNE and NE including $\mathrm{N}$ can be utilized, which means that the winds from two wind directions can't be utilized compared to the buildings with $\alpha=135^{\circ}$. In this work, it is assumed that the winds from the same wind directions as the buildings with $\alpha=135^{\circ}$ can be utilized in the case of the buildings with $\alpha=180^{\circ}$. Since the buildings layout direction is parallel to the West (W) and East (E) in the case of the buildings with $\alpha=180^{\circ}$, it is considered that the winds from these wind directions can't be utilized.

Assuming the symmetry to the main wind direction, the wind speed distributions around the buildings for the inflow angles $(\beta)$ of $22.5^{\circ}, 45^{\circ}$ and $67.5^{\circ}$ are simulated to evaluate the effect of six angular inflows on the wind

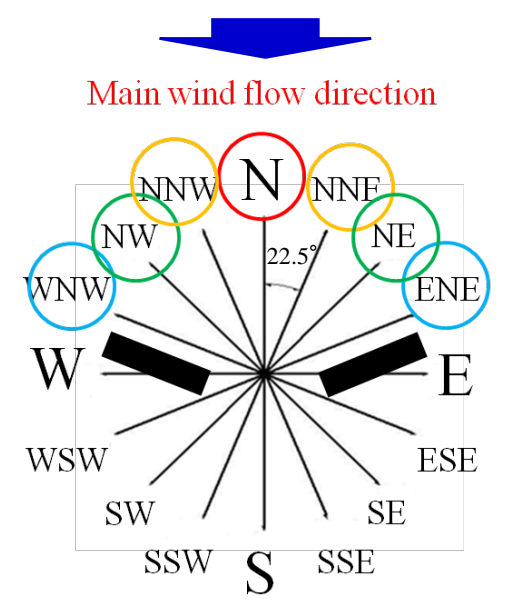

Figure 2. Wind direction for blowing in intervening space between buildings. 
speed distribution in the case of buildings with $\alpha=135^{\circ}$ and $180^{\circ}$. When $\alpha$ is $90^{\circ}$, the wind speed distributions around the buildings for $\beta=22.5^{\circ}$ and $45^{\circ}$ are simulated to evaluate the effect of four angular inflows on the wind speed distribution. Wind speed at inlet of the model is set by Equations (6) and (7), when the effect of inflow angle is considered.

$$
\begin{aligned}
& U=\cos \beta \times U_{0} \times\left(\frac{z}{30}\right)^{0.25} \\
& V=\sin \beta \times U_{0} \times\left(\frac{z}{30}\right)^{0.25}
\end{aligned}
$$

where $V$ is the wind speed in $y$ direction, $\beta$ is inflow angle.

\section{Results and Discussion}

\subsection{Wind Speed Distribution around Buildings}

The contour of wind speed distribution in $x$ direction $(U)$ around the buildings with $\alpha=135^{\circ}$ for $U_{0}=10.0 \mathrm{~m} / \mathrm{s}$ at $z=30 \mathrm{~m}$ are given in Figure 3 and they are on $x-y$ cross section of the building. It shows the distribution of $U$ in the case of $\beta=0^{\circ}$, (i.e. the model faces the main wind direction). In this model, $x=0 \mathrm{~m}$ and $y=0 \mathrm{~m}$ is located at the center of distance between the nearest edge of adjacent two buildings. In this Figure 3, black lines mean the separation lines, which distinguish the different calculation domain in the model used for numerical simulation. It has been observed that the wind is accelerated within the intervening space between the buildings since some wind is over the $U_{0}$ of $10.0 \mathrm{~m} / \mathrm{s}$.

It is important to decide the location point of wind turbine in order to obtain the accelerated wind. In our previous studies [1] [2], the wind acceleration was confirmed and evaluated in the swept rotor area at $x / L=1.25$, 1.875 and 2.50. Therefore, the present paper focuses on location points. Since the $U_{h \text {, ave }}$ is an important wind speed which is used for the power curve to calculate the power output of wind turbine, Tables 3-5 list the

\begin{tabular}{|c|c|c|c|c|c|c|}
\hline \multirow{2}{*}{$\begin{array}{c}U_{0}(\mathrm{~m} / \mathrm{s}) \\
x / L(-)\end{array}$} & \multicolumn{2}{|c|}{3.0} & \multicolumn{2}{|c|}{4.0} & \multicolumn{2}{|c|}{5.0} \\
\hline & $U_{h, \text { ave }} / U_{0}(-)$ & $P(\mathrm{~kW})$ & $U_{h, a v e} / U_{0}(-)$ & $P(\mathrm{~kW})$ & $U_{h, a v e} / U_{0}(-)$ & $P(\mathrm{~kW})$ \\
\hline 1.25 & 1.10 & 1.35 & 1.10 & 3.70 & 1.10 & 7.80 \\
\hline 1.875 & 1.09 & 1.29 & 1.09 & 3.53 & 1.09 & 7.43 \\
\hline 2.5 & 1.06 & 1.16 & 1.06 & 3.21 & 1.06 & 6.77 \\
\hline$U_{0}(\mathrm{~m} / \mathrm{s})$ & \multicolumn{2}{|c|}{6.0} & \multicolumn{2}{|c|}{7.0} & \multicolumn{2}{|c|}{8.0} \\
\hline$x / L(-)$ & $U_{h, \text { ave }} / U_{0}(-)$ & $P(\mathrm{~kW})$ & $U_{h, a v e} / U_{0}(-)$ & $P(\mathrm{~kW})$ & $U_{h, a v e} / U_{0}(-)$ & $P(\mathrm{~kW})$ \\
\hline 1.25 & 1.10 & 14.10 & 1.10 & 7.80 & 1.10 & 14.10 \\
\hline 1.875 & 1.09 & 13.43 & 1.09 & 7.43 & 1.09 & 13.43 \\
\hline 2.5 & 1.06 & 12.26 & 1.06 & 6.77 & 1.06 & 12.26 \\
\hline$U_{0}(\mathrm{~m} / \mathrm{s})$ & \multicolumn{2}{|c|}{9.0} & \multicolumn{2}{|c|}{10.0} & \multicolumn{2}{|c|}{11.0} \\
\hline$x / L(-)$ & $U_{h, \text { ave }} / U_{0}(-)$ & $P(\mathrm{~kW})$ & $U_{h, a v e} / U_{0}(-)$ & $P(\mathrm{~kW})$ & $U_{h, \text { ave }} / U_{0}(-)$ & $P(\mathrm{~kW})$ \\
\hline 1.25 & 1.09 & 49.86 & 1.09 & 52.36 & 1.09 & 51.46 \\
\hline 1.875 & 1.07 & 46.72 & 1.07 & 52.55 & 1.07 & 51.64 \\
\hline 2.5 & 1.03 & 41.77 & 1.03 & 52.87 & 1.04 & 51.95 \\
\hline$U_{0}(\mathrm{~m} / \mathrm{s})$ & \multicolumn{2}{|c|}{12.0} & & & & \\
\hline$x / L(-)$ & $U_{h, \text { ave }} / U_{0}(-)$ & $P(\mathrm{~kW})$ & & & & \\
\hline 1.25 & 1.10 & 50.57 & & & & \\
\hline 1.875 & 1.08 & 50.71 & & & & \\
\hline 2.5 & 1.05 & 50.98 & & & & \\
\hline
\end{tabular}

Table 3. Comparison of $U_{\mathrm{h} \text {,ave }}$ and $P$ among different $U_{0}$ at $x / L=1.25,1.875,2.50$ for $\alpha=90^{\circ}$ and $\beta=0^{\circ}$. 
Table 4. Comparison of $U_{\mathrm{h}, \text { ave }}$ and $P$ among different $U_{0}$ at $x / L=1.25,1.875,2.50$ for $\alpha=135^{\circ}$ and $\beta=0^{\circ}$.

\begin{tabular}{|c|c|c|c|c|c|c|}
\hline \multirow{2}{*}{$\begin{array}{c}U_{0}(\mathrm{~m} / \mathrm{s}) \\
x / L(-)\end{array}$} & \multicolumn{2}{|c|}{3.0} & \multicolumn{2}{|c|}{4.0} & \multicolumn{2}{|c|}{5.0} \\
\hline & $U_{h, \text { ave }} / U_{0}(-)$ & $P(\mathrm{~kW})$ & $U_{h, \text { ave }} / U_{0}(-)$ & $P(\mathrm{~kW})$ & $U_{h, a v e} / U_{0}(-)$ & $P(\mathrm{~kW})$ \\
\hline 1.25 & 1.09 & 1.29 & 1.09 & 3.56 & 1.09 & 7.52 \\
\hline 1.875 & 1.08 & 1.24 & 1.08 & 3.45 & 1.08 & 7.30 \\
\hline 2.5 & 1.05 & 1.12 & 1.06 & 3.24 & 1.06 & 6.86 \\
\hline$U_{0}(\mathrm{~m} / \mathrm{s})$ & \multicolumn{2}{|c|}{6.0} & \multicolumn{2}{|c|}{7.0} & \multicolumn{2}{|c|}{8.0} \\
\hline$x / L(-)$ & $U_{h, \text { ave }} / U_{0}(-)$ & $P(\mathrm{~kW})$ & $U_{h, \text { ave }} / U_{0}(-)$ & $P(\mathrm{~kW})$ & $U_{h, a v e} / U_{0}(-)$ & $P(\mathrm{~kW})$ \\
\hline 1.25 & 1.08 & 13.23 & 1.09 & 22.34 & 1.09 & 34.12 \\
\hline 1.875 & 1.07 & 12.84 & 1.08 & 21.69 & 1.07 & 32.18 \\
\hline 2.5 & 1.05 & 12.08 & 1.05 & 19.83 & 1.04 & 29.41 \\
\hline$U_{0}(\mathrm{~m} / \mathrm{s})$ & \multicolumn{2}{|c|}{9.0} & \multicolumn{2}{|c|}{10.0} & \multicolumn{2}{|c|}{11.0} \\
\hline$x / L(-)$ & $U_{h, \text { ave }} / U_{0}(-)$ & $P(\mathrm{~kW})$ & $U_{h, \text { ave }} / U_{0}(-)$ & $P(\mathrm{~kW})$ & $U_{h, a v e} / U_{0}(-)$ & $P(\mathrm{~kW})$ \\
\hline 1.25 & 1.08 & 48.01 & 1.09 & 52.39 & 1.08 & 48.01 \\
\hline 1.875 & 1.06 & 45.27 & 1.08 & 52.48 & 1.06 & 45.27 \\
\hline 2.5 & 1.03 & 41.37 & 1.05 & 52.68 & 1.03 & 41.37 \\
\hline$U_{0}(\mathrm{~m} / \mathrm{s})$ & \multicolumn{2}{|c|}{12.0} & & & & \\
\hline$x / L(-)$ & $U_{h, a v e} / U_{0}(-)$ & $P(\mathrm{~kW})$ & & & & \\
\hline 1.25 & 1.09 & 52.39 & & & & \\
\hline 1.875 & 1.08 & 52.49 & & & & \\
\hline 2.5 & 1.05 & 52.68 & & & & \\
\hline
\end{tabular}

Table 5. Comparison of $U_{\mathrm{h}, \text { ave }}$ and $P$ among different $U_{0}$ at $x / L=1.25,1.875,2.50$ for $\alpha=180^{\circ}$ and $\beta=0^{\circ}$.

\begin{tabular}{|c|c|c|c|c|c|c|}
\hline \multirow{2}{*}{$\begin{array}{c}U_{0}(\mathrm{~m} / \mathrm{s}) \\
x / L(-)\end{array}$} & \multicolumn{2}{|c|}{3.0} & \multicolumn{2}{|c|}{4.0} & \multicolumn{2}{|c|}{5.0} \\
\hline & $U_{h, a v e} / U_{0}(-)$ & $P(\mathrm{~kW})$ & $U_{h, a v e} / U_{0}(-)$ & $P(\mathrm{~kW})$ & $U_{h, \text { ave }} / U_{0}(-)$ & $P(\mathrm{~kW})$ \\
\hline 1.25 & 1.15 & 1.57 & 1.15 & 4.30 & 1.15 & 9.02 \\
\hline 1.875 & 1.15 & 1.56 & 1.15 & 4.25 & 1.15 & 8.97 \\
\hline 2.5 & 1.13 & 1.48 & 1.13 & 4.07 & 1.13 & 8.54 \\
\hline$U_{0}(\mathrm{~m} / \mathrm{s})$ & \multicolumn{2}{|c|}{6.0} & \multicolumn{2}{|c|}{7.0} & \multicolumn{2}{|c|}{8.0} \\
\hline$x / L(-)$ & $U_{h, a v e} / U_{0}(-)$ & $P(\mathrm{~kW})$ & $U_{h, a v e} / U_{0}(-)$ & $P(\mathrm{~kW})$ & $U_{h, \text { ave }} / U_{0}(-)$ & $P(\mathrm{~kW})$ \\
\hline 1.25 & 1.15 & 16.33 & 1.15 & 26.74 & 1.15 & 40.50 \\
\hline 1.875 & 1.15 & 16.15 & 1.15 & 26.53 & 1.15 & 40.28 \\
\hline 2.5 & 1.13 & 15.39 & 1.13 & 25.25 & 1.13 & 38.44 \\
\hline$U_{0}(\mathrm{~m} / \mathrm{s})$ & \multicolumn{2}{|c|}{9.0} & \multicolumn{2}{|c|}{10.0} & \multicolumn{2}{|c|}{11.0} \\
\hline$x / L(-)$ & $U_{h, \text { ave }} / U_{0}(-)$ & $P(\mathrm{~kW})$ & $U_{h, \text { ave }} / U_{0}(-)$ & $P(\mathrm{~kW})$ & $U_{h, \text { ave }} / U_{0}(-)$ & $P(\mathrm{~kW})$ \\
\hline 1.25 & 1.15 & 52.78 & 1.15 & 51.88 & 1.15 & 50.96 \\
\hline 1.875 & 1.15 & 52.82 & 1.14 & 51.92 & 1.15 & 51.00 \\
\hline 2.5 & 1.13 & 52.94 & 1.12 & 52.09 & 1.13 & 51.18 \\
\hline$U_{0}(\mathrm{~m} / \mathrm{s})$ & \multicolumn{2}{|c|}{12.0} & & & & \\
\hline$x / L(-)$ & $U_{h, a v e} / U_{0}(-)$ & $P(\mathrm{~kW})$ & & & & \\
\hline 1.25 & 1.15 & 50.04 & & & & \\
\hline 1.875 & 1.15 & 50.08 & & & & \\
\hline 2.5 & 1.13 & 50.27 & & & & \\
\hline
\end{tabular}




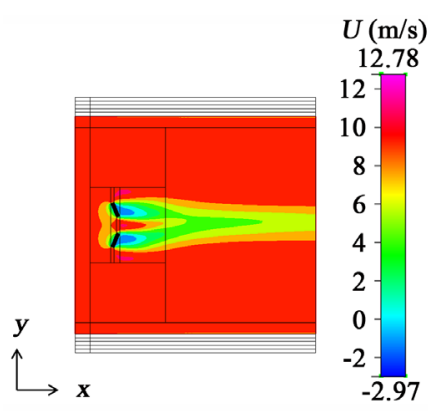

Figure 3. Contour of wind speed $U$ distribution around buildings at $z=30 \mathrm{~m}$ on $x-y$ cross section $\left(\alpha=135^{\circ}, \beta=0^{\circ}, U_{0}=10.0 \mathrm{~m} / \mathrm{s}\right)$.

variation of $U_{h, \text { ave }}$ in the swept rotor area at $x / L=1.25,1.875$ and 2.50 under the different $U_{0}$ conditions for $\alpha=$ $90^{\circ}, 135^{\circ}$ and $180^{\circ}$, respectively. In these tables, $U_{h, \text { ave }}$ is estimated under the condition that $\beta$ is $0^{\circ}$. The power output of wind turbine $P$ corresponding to each $U_{h \text {, ave }}$ is also listed in these tables.

From these tables, it is seen that $U_{h, \text { ave }}$ is greater than $U_{0}$ for every condition. Hence, it is revealed that the proposed building model can provide the wind acceleration under the investigated conditions. Considering the location point of wind turbine, the highest $U_{h, \text { ave }}$ is obtained at $x / L=1.25$ for every $\alpha$ and $U_{0}$ condition though $P$ is relatively smaller compared to the other $x / L$ under the condition that $U_{0}$ is over $10.0 \mathrm{~m} / \mathrm{s}$. Since the rated wind speed of supposed wind turbine is $10.0 \mathrm{~m} / \mathrm{s}$, the $P$ decreases with the increase in wind speed gradually under the condition that $U_{0}$ is over $10.0 \mathrm{~m} / \mathrm{s}$ according to the power curve [1]. This work intends to utilize the wind power by accelerating the low speed wind effectively, resulting that the location point of wind turbine is decided at $x / L=1.25$. In the next section, the power generation characteristics of wind turbine in the built environment is evaluated at $x / L=1.25$.

Since the wind blows from different directions actually, it is necessary to evaluate the effect of wind direction on wind speed distribution around buildings. In this study, the wind speed distributions around the buildings for $\beta=22.5^{\circ}, 45^{\circ}$ and $67.5^{\circ}$ are simulated. As an example of the simulation results, the contour of wind speed $U$ distribution around buildings for $U_{0}=10.0 \mathrm{~m} / \mathrm{s}$ at $z=30 \mathrm{~m}$ on $x-y$ cross section for angular inflow direction of $\beta=$ $45^{\circ}$ are given in Figure 4. Since the wind speed at the inlet of the model is divided into two directions of $x$ and $y$ for the angular inflow case in this study, $U$ at $z=30 \mathrm{~m}$ is $7.07 \mathrm{~m} / \mathrm{s}$ when the wind reaches the building. Although the wind blows through the intervening space between the buildings, the wind acceleration is not high. Hence, the location of open tip of building model is important.

\subsection{Power Generation Performance of Wind Turbine Located in Proposed Building Layouts in Actual Cities of Japan}

To optimize the building layout for increasing electrical energy output of wind turbine assumed to be installed in actual cities of Japan, the wind speed data of five years (from 2010 to 2014) for Fukushima city and Tsu city are used from the Japan Meteorological Agency [26]. In estimation of the power generation characteristics of the building model, the location of wind turbine in proposed building layouts should be decided first. According to the wind speed data of the Japan Meteorological Agency [26], the main wind direction throughout the year for Fukushima city and Tsu city which is decided by the hourly measurement data from 2010 to 2014 is NW. In this study, the open tip of building model is located to be faced with the main wind direction (refer to Figure 2). For example, West-South-West (WSW), W, WNW, NNW, N and NNE in addition to NW are the available wind directions when $\alpha$ is $135^{\circ}$. Therefore, the proposed building layouts make the nozzle by utilizing the wind speed directions. In this work, it is assumed that the wind blowing from the directions except for the above described wind directions can't be utilized for power generation of wind turbine. The different inflow angle conditions are considered in the simulation for finding the suitable wind direction in the proposed building layouts.

The hourly data on wind speed and direction are obtained for Fukushima city and Tsu city from the Japan Meteorological Agency [26]. These data are used as inputs in the simulation for finding the wind turbine power output at a location of wind turbine in the proposed building layouts. The hourly power energy outputs of wind turbine located at location of the proposed building layout with $\alpha=135^{\circ}$ in the case of Fukushima city and Tsu city are given in Figure 5 and Figure 6, respectively. In these figures, the hourly change in statistically-veraged 


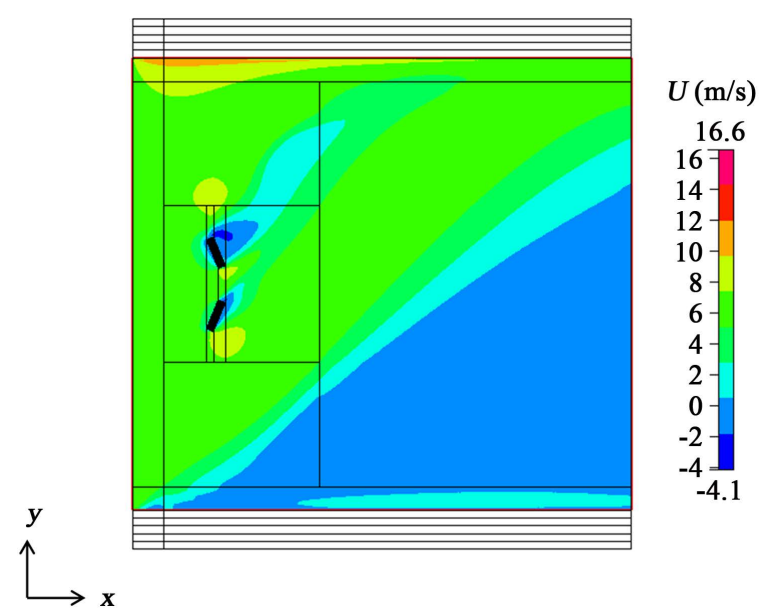

Figure 4. Contour of wind speed $U$ distribution around buildings at $z=30 \mathrm{~m}$ on $x-y$ cross section $\left(\alpha=135^{\circ}, \beta=45^{\circ}, U_{0}=10.0 \mathrm{~m} / \mathrm{s}\right)$.

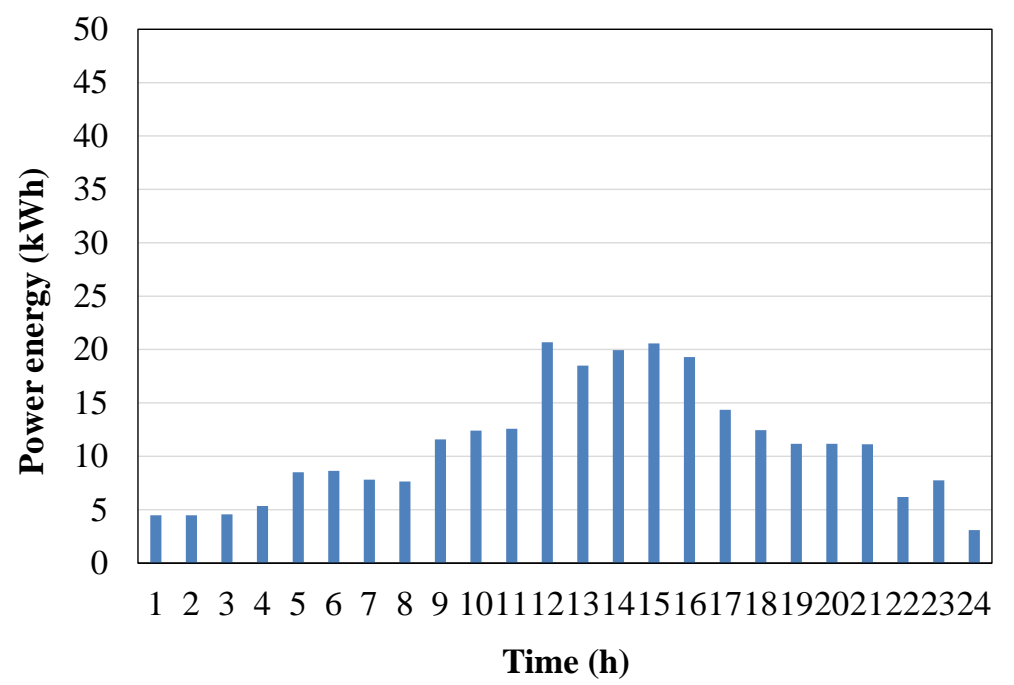

Figure 5. Time change in power energy of wind turbine in January in the case of installing building model in Fukushima city $\left(\alpha=135^{\circ}\right)$.

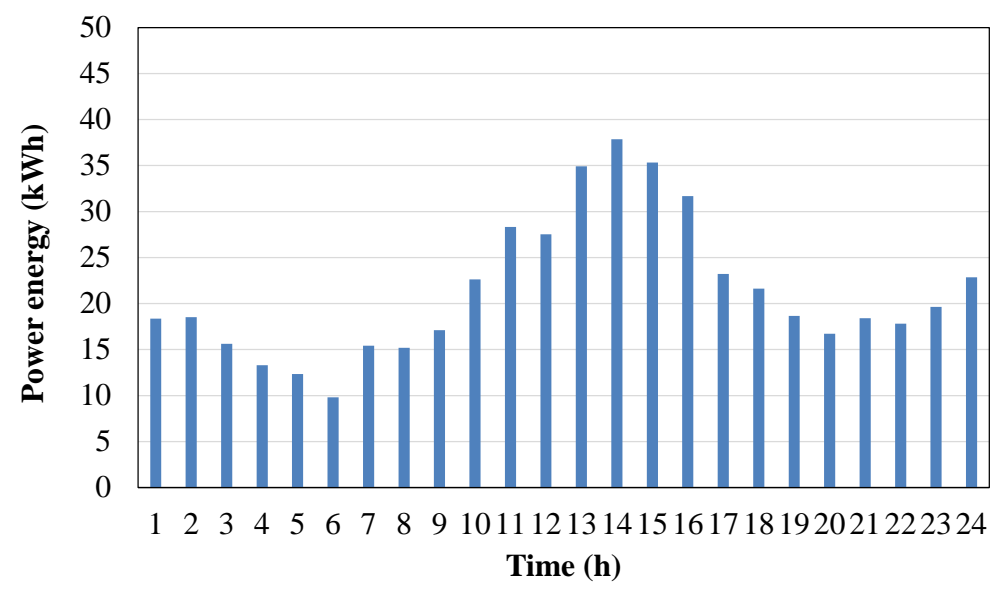

Figure 6. Time change in power energy of wind turbine in January in the case of installing building model in Tsu city $\left(\alpha=135^{\circ}\right)$. 
day in January is shown as an example. From these figures, it is observed that the higher power energy of wind turbine is obtained in the daytime. This result is also confirmed from the other months. In these two cities, the wind energy is mainly obtained in the daytime. However, the hourly power energy output of wind turbine in the case of Tsu city has peaks in nighttime as well as daytime while there is only one peak in the case of Fukushima city. Since Tsu city is located facing Isewan bay, the wind blowing between land and bay is occurred resulting from the temperature difference between land and bay in the middle of daytime as well as that of nighttime.

Table 6 and Table 7 list the monthly and annual wind power energy output of wind turbine in the building layouts with $\alpha=90^{\circ}, 135^{\circ}$ and $180^{\circ}$ in the case of Fukushima city and Tsu city, respectively.

From these tables, it is observed that the wind power energy of wind turbine in the building layout with $\alpha=$ $135^{\circ}$ is the highest among the investigated $\alpha$ conditions. Though $U_{h \text {, ave }} / U_{0}$ obtained under the different $U_{0}$ conditions for the building layout with $\alpha=180^{\circ}$ is relatively higher than that with $\alpha=90^{\circ}$ and $135^{\circ}$ according to Tables 3-5, the difference among them is small. Therefore, it is believed that the optimum building layout is decided by the wind blowing from angular inflow directions.

Table 8 lists the comparison of $P$ at $x / L=1.25$ under different $\beta$ conditions among $\alpha=90^{\circ}, 135^{\circ}$ and $180^{\circ}$. In this table, $P$ obtained under $U_{0}=10.0 \mathrm{~m} / \mathrm{s}$ condition are shown. It is found that $P$ for $\beta=45^{\circ}$ obtained under $\alpha=$ $135^{\circ}$ condition is much higher compared to the other $\alpha$ conditions.

In addition, it is clarified from Table 6 and Table 7 that the wind power energy output in winter season is higher while that in summer season is lower irrespective of $\alpha$ as well as investigated city. The wind direction is changed throughout the year. Figure 7 and Figure 8 show the frequency distribution of wind speed direction in Fukushima city in January and August, respectively. From these figures, the direction of main wind speed in January and August are WNW and NE, respectively. On the other hand, the direction of main wind speed throughout the year is NW. In this study, it is assumed that the wind blowing from the restricted wind directions can be utilized for power generation of wind turbine while the amount of wind power energy production is estimated to be zero for the wind blowing from the other directions. WNW is the next direction to NW, resulting that the large wind energy can be obtained under every $\alpha$ condition. On the other hand, NE and ENE which are two directions conducing larger wind flow in August are neglected in the estimation of wind power energy, resulting in the lower wind power energy output in August.

Table 6. Monthly and annual wind power energy of wind turbine in the building layouts with $\alpha=90^{\circ}, 135^{\circ}$ and $180^{\circ}$ for Fukushima city.

\begin{tabular}{|c|c|c|c|c|}
\hline$\alpha\left(\left(^{\circ}\right)\right.$ & January $(\mathrm{kW} \cdot \mathrm{h})$ & February $(\mathrm{kW} \cdot \mathrm{h})$ & $\operatorname{March}(\mathrm{kW} \cdot \mathrm{h})$ & April $(\mathrm{kW} \cdot \mathrm{h})$ \\
\hline 90 & 8044 & 5545 & 6978 & 6430 \\
\hline 135 & 8193 & 5734 & 7216 & 6685 \\
\hline 180 & 5512 & 5940 & 9516 & 7608 \\
\hline$\alpha\left({ }^{\circ}\right)$ & May $(\mathrm{kW} \cdot \mathrm{h})$ & June $(\mathrm{kW} \cdot \mathrm{h})$ & July (kW·h) & August $(\mathrm{kW} \cdot \mathrm{h})$ \\
\hline 90 & 3417 & 1033 & 354 & 333 \\
\hline 135 & 3826 & 1034 & 361 & 341 \\
\hline 180 & 6100 & 855 & 299 & 1600 \\
\hline$\alpha\left({ }^{\circ}\right)$ & September $(\mathrm{kW} \cdot \mathrm{h})$ & October $(\mathrm{kW} \cdot \mathrm{h})$ & November $(\mathrm{kW} \cdot \mathrm{h})$ & December $(\mathrm{kW} \cdot \mathrm{h})$ \\
\hline 90 & 1412 & 4993 & 4969 & 8086 \\
\hline 135 & 1518 & 5367 & 5037 & 8342 \\
\hline 180 & 1177 & 3294 & 3634 & 3604 \\
\hline$\alpha\left(\left(^{\circ}\right)\right.$ & Year $(\mathrm{kW} \cdot \mathrm{h})$ & & & \\
\hline 90 & 51,595 & & & \\
\hline 135 & 53,655 & & & \\
\hline 180 & 49,140 & & & \\
\hline
\end{tabular}




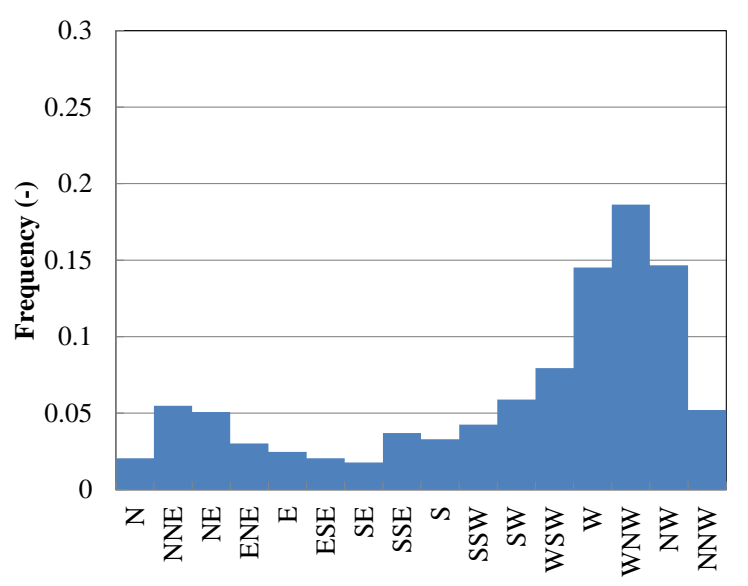

Figure 7. Frequency distribution of wind speed direction in January in Fukushima city.

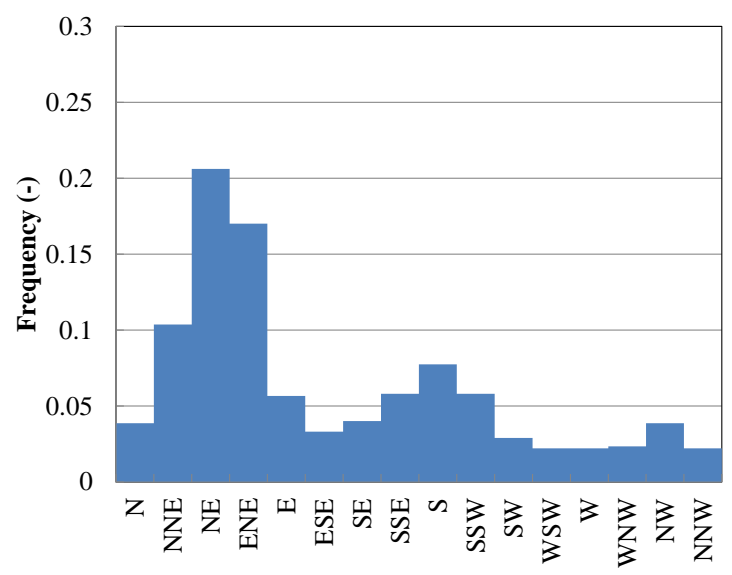

Figure 8. Frequency distribution of wind speed direction in August in Fukushima city.

Table 7. Monthly and annual wind power energy of wind turbine in the building layouts with $\alpha=90^{\circ}, 135^{\circ}$ and $180^{\circ}$ for Tsu city.

\begin{tabular}{|c|c|c|c|c|}
\hline$\alpha\left(\left(^{\circ}\right)\right.$ & January $(\mathrm{kW} \cdot \mathrm{h})$ & February $(\mathrm{kW} \cdot \mathrm{h})$ & $\operatorname{March}(\mathrm{kW} \cdot \mathrm{h})$ & April $(\mathrm{kW} \cdot \mathrm{h})$ \\
\hline 90 & 14,900 & 13,220 & 12,696 & 11,212 \\
\hline 135 & 15,898 & 14,608 & 13,367 & 12,164 \\
\hline 180 & 14,408 & 12,249 & 12,022 & 10,376 \\
\hline$\alpha\left(^{\circ}\right)$ & May $(\mathrm{kW} \cdot \mathrm{h})$ & June $(\mathrm{kW} \cdot \mathrm{h})$ & July (kW·h) & August $(\mathrm{kW} \cdot \mathrm{h})$ \\
\hline 90 & 9004 & 936 & 4761 & 5223 \\
\hline 135 & 9954 & 958 & 4833 & 5438 \\
\hline 180 & 8563 & 843 & 4418 & 4824 \\
\hline$\alpha\left({ }^{\circ}\right)$ & September $(\mathrm{kW} \cdot \mathrm{h})$ & October $(\mathrm{kW} \cdot \mathrm{h})$ & November $(\mathrm{kW} \cdot \mathrm{h})$ & December $(\mathrm{kW} \cdot \mathrm{h})$ \\
\hline 90 & 3953 & 7506 & 8756 & 13,866 \\
\hline 135 & 4258 & 7905 & 9130 & 14,719 \\
\hline 180 & 3792 & 6980 & 8158 & 13,020 \\
\hline$\alpha\left({ }^{\circ}\right)$ & Year $(\mathrm{kW} \cdot \mathrm{h})$ & & & \\
\hline 90 & 106,034 & & & \\
\hline 135 & 113,233 & & & \\
\hline 180 & 99,652 & & & \\
\hline
\end{tabular}


Figure 9 and Figure 10 show the frequency distribution of wind speed direction in Tsu city in January and August, respectively. Since the same phenomena as the Fukushima city can be observed in the case of Tsu city, the wind energy output in winter season is higher while that in summer season is lower.

Comparing the annual wind energy of output of turbine in the building layouts between Fukushima city and Tsu city, the annual wind energy for Tsu city is approximately twice as much as that for Fukushima city. According to the wind speed data of the Japan Meteorological Agency [26], the annual mean wind speed for Tsu city and Fukushima city are $3.4 \mathrm{~m} / \mathrm{s}$ and $2.4 \mathrm{~m} / \mathrm{s}$, respectively. Since the wind power of wind turbine is derived from the wind consisting of the cube of wind speed, the gap of wind speed brings about the big difference of wind power energy between the two cities.

From the investigation in this study, it is revealed that the proposed building model performs the highest power generation production under $\alpha=135^{\circ}$ condition. The power generation characteristics of wind turbine in the building layouts assumed to be located in actual cities have been clarified. The actual wind condition influences the power generation performance of proposed building model. This study will continue to verify the feasibility of the proposed model with more wind speed data in the near future.

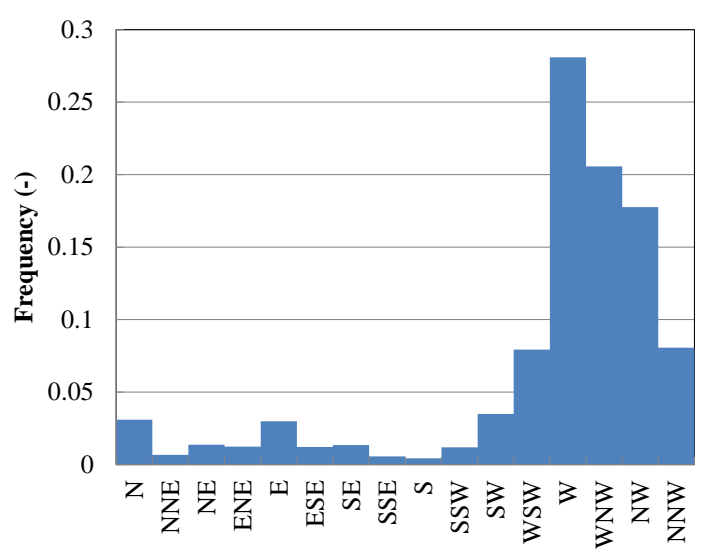

Figure 9. Frequency distribution of wind speed direction in January in Tsu city.

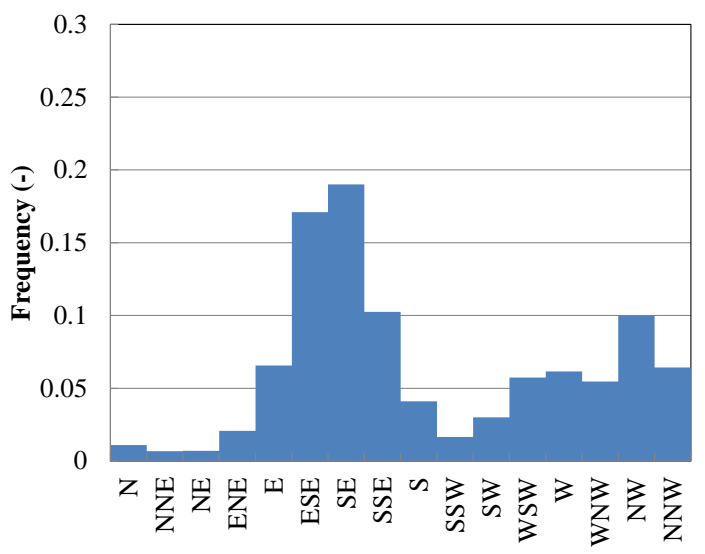

Figure 10. Frequency distribution of wind speed direction in August in Tsu city.

Table 8. Comparison of $P$ under different $\beta$ conditions among $\alpha=90^{\circ}, 135^{\circ}$ and $180^{\circ}\left(U_{0}=10.0 \mathrm{~m} / \mathrm{s}, x / L=1.25\right)$.

\begin{tabular}{cccc}
\hline$\beta\left(^{\circ}\right)$ & 22.5 & 45 & 67.5 \\
\hline$\alpha\left(^{\circ}\right)$ & $P(\mathrm{~kW})$ & $P(\mathrm{~kW})$ & $P(\mathrm{~kW})$ \\
\hline 90 & 5.29 & 0.62 & - \\
135 & 5.29 & 1.26 & 0.21 \\
180 & 5.34 & 0.21 & 0.37 \\
\hline
\end{tabular}




\section{Conclusions}

In this study, building topologies/orientations in a smart city are investigated for finding out the wind speed profile in the built environment. The analysis of wind speed distribution in the built environment is very important for not only to find the mechanical wind stress but also to find the energy output from the built environment located wind turbines. This analysis is also useful for designing the building layouts in such a way to make a nozzle of the wind by using wind directions and then finding out the proper location of the wind turbine in the built environment. In this work, the objective is to optimize the building layout for increasing electrical energy output of wind turbine assumed to be installed in the actual cities of the Japan. The wind speed distribution across the buildings is simulated using CFD software. The output power of wind turbine is estimated by using the power curve of a real commercial wind turbine and the wind speed distribution around buildings using the wind speed data for Fukushima city and Tsu city. As a result, the following conclusions have been obtained:

1) The proposed building models with $\alpha=90^{\circ}, 135^{\circ}, 180^{\circ}$ can provide the $U_{h \text {, ave }}$ over $U_{0}$ at $x / L=1.25,1.875$ and 2.50 under the different $U_{0}$ conditions for the wind blowing from the main wind direction, i.e., $\beta=0^{\circ}$.

2) Though the wind blowing for angular inflow direction is not accelerated well by the proposed building models, the optimum $\alpha$ which is $135^{\circ}$ is decided by the wind blowing from angular inflow direction.

3) In the case of installing the proposed building model in Fukushima city and Tsu city, the wind power energy output in winter season is higher while that in summer season is lower irrespective of $\alpha$. The interaction between the change in frequency distribution of wind speed direction throughout the year and the location of open tip of building model decides the power generation characteristics of the proposed building model.

4) It is revealed that the annual wind power energy of wind turbine in the building layouts is influenced by the annual mean wind speed significantly.

\section{Acknowledgements}

This study was financially supported by MAYEKAWA HOUONKAI FOUNDATION. The authors thank for its cooperation.

\section{References}

[1] Nishimura, A., Ito, T., Murata, J., Ando, T., Kamada, Y., Hirota, M. and Kolhe, M. (2013) Wind Turbine Power Output Assessment in Built Environment. Smart Grid and Renewable Energy, 4, 1-10. http://dx.doi.org/10.4236/sgre.2013.41001

[2] Nishimura, A., Ito, T., Kakita, M., Murata, J., Ando, T., Kamada, Y., Hirota, M. and Kolhe, M. (2014) Impact of Building Layouts on Wind Turbine Power Output in the Built Environment: A Case Study of Tsu City. Journal of the Japan Institute of Energy, 94, 315-322. http://dx.doi.org/10.3775/jie.93.315

[3] Nishimura, A. and Kolhe, M. (2015) A Study on Assessment of Power Output by Integrating Wind Turbine and Photovoltaic Energy Sources with Futuristic Smart Buildings, Global Warming-Causes, Impacts and Remedies. In: Singh, B.R., Ed., Global Warming—Causes, Impacts and Remedies, InTech, Rijeka, Chapter 7, 139-167.

[4] Zhenglin, Z., Hongyan, W., Xiaolong, B. and Hongxiang, X. (2011) Study and Application of the Wind Power on the Tall Building Rooftops in Large Cities. Proceedings of 2011 International Conference (IEEE) on Materials for Renewable Energy \& Environment (ICMREE), Shanghai, 566-569. http://dx.doi.org/10.1109/ICMREE.2011.5930876

[5] Yoshie, R., Tominaga, Y., Mochida, A., Kataoka, H. and Yoshikawa, H. (2005) CFD Simulation of Flow-Field around a High-Rise Building Located in Surrounding City Blocks Part (1) Outline of Experiment and Calculation, Influences of Various Calculation Conditions. Wind Engineers, 30, 133-134.

[6] Murakami, S., Hibi, K. and Mochida, A. (1991) Three Dimensional Analysis of Turbulent Flow Field around Street Blocks by Means of Large Eddy Simulation (Part II). Journal of Architecture, Planning and Environmental Engineering, 425, 11-19.

[7] Kataoka, H. and Mizuno, M. (1998) Numerical Simulation of Separating Flow around a Body Using Artificial Compressibility Method. Journal of Architecture, Planning and Environmental Engineering, 504, 63-70.

[8] Nishimura, K., Yasuda, R. and Ito, S. (1999) An Experimental and Numerical Study of Concentration Prediction around a Building, Part II Numerical Simulation by $k-\varepsilon$ Model. Japan Society for Atmospheric Environment, 34, 103122.

[9] Nozu, T. and Tamura, T. (2000) Application of Computational Fluid Technique with High Accuracy and Conservation Property to the Wind Resistant Problems of Buildings and Structures, Part 3 Analysis of the Flows and the Wind Pres- 
sure around a High-Rise Building in the Turbulent Boundary Layer. Journal of Structural and Construction Engineering, 538, 65-72.

[10] Nozu, T. and Tamura, T. (1998) Application of Computational Fluid Technique with High Accuracy and Conservation Property to the Wind Resistant Problems of Buildings and Structures, Part 2 Vortex Structures and Aerodynamic Characteristics around a Three-Dimensional Square Prism on a Ground Plane. Journal of Structural and Construction Engineering, 503, 37-43.

[11] Kose, D.A., Fauconnier, D. and Dick, E. (2011) ILES of Flow over Low-Rise Buildings: Influence of Inflow Conditions on the Quality of the Mean Pressure Distribution Prediction. Journal of Wind Engineering and Industrial Aerodynamics, 99, 1056-1068. http://dx.doi.org/10.1016/j.jweia.2011.07.008

[12] Meng, Y. and Hibi, K. (1997) Turbulence Characteristics and Organized Motions on the Flat Roof of a High-Rise Building. Journal of Wind Engineering, 72, 21-34. http://dx.doi.org/10.5359/jawe.1997.72_21

[13] Meng, Y. and Oikawa, S. (1997) A Wind-Tunnel Study of the Flow and Diffusion within Model Urban Canopies. Journal of Japan Society for Atmospheric Environment, 32, 136-147.

[14] Oikawa, S., Ishihara, T., Yasuda, R., Nishimura, K. and Hase, M. (1999) An Experimental and Numerical Study of Concentration Prediction around a Building, Part I Wind-Tunnel Study. Journal of Japan Society for Atmospheric Environment, 34, 123-136.

[15] Zaki, S.A., Hagishima, A. and Tanimoto, J. (2012) Experimental Study of Wind-Induced Ventilation in Urban Building of Cue Arrays with Various Layouts. Journal of Wind Engineering and Industrial Aerodynamics, 103, 31-40. http://dx.doi.org/10.1016/j.jweia.2012.02.008

[16] Ouammi, A., Dagdougui, H., Sacile, R. and Mimet, A. (2010) Monthly and Seasonal Assessment of Wind Energy Characteristics at Four Monitored Locations in Liguria Region (Italy). Renewable and Sustainable Energy Reviews, 14, 1959-1968. http://dx.doi.org/10.1016/j.rser.2010.04.015

[17] Oyedepo, S.O., Adaramola, M.S. and Paul, S.S. (2012) Analysis of Wind Speed Data and Wind Energy Potential in Three Selected Locations in South-East Nigeria. International Journal of Energy and Environmental Engineering, 3, Article No.: 7.

[18] Olaofe, Z.O. and Folly, K.A. (2013) Wind Energy Analysis Based on Turbine and Developed Site Power Curves: A Case-Study of Darling City. Renewable Energy, 53, 306-318. http://dx.doi.org/10.1016/j.renene.2012.11.003

[19] Saito, S., Saito, K. and Sekizuka, S. (2006) A Discussion on Prediction of Wind Conditions and Power Generation with the Weibull Distribution. JSME International Journal Series B, 49, 458-464. http://dx.doi.org/10.1299/jsmeb.49.458

[20] Khadem, S.K. and Hussain, M. (2006) A Pre-Feasibility Study of Wind Resources in Kutubdia Island, Bangladesh. Renewable Energy, 31, 2329-2341. http://dx.doi.org/10.1016/j.renene.2006.02.011

[21] Firtin, E., Guler, O. and Akdag, S.A. (2011) Investigation of Wind Shear Coefficient and Their Effect on Electrical Energy Generation. Applied Energy, 88, 4097-4105. http://dx.doi.org/10.1016/j.apenergy.2011.05.025

[22] Rocha, P.A.C., Sousa, R.C. and Andrade, C.F. (2012) Comparison of Seven Numerical Methods for Determining Weibull Parameters for Wind Energy Generation in the Northeast Region of Brazil. Applied Energy, 89, 395-400. http://dx.doi.org/10.1016/j.apenergy.2011.08.003

[23] Usta, I. and Kantar, Y.M. (2012) Analysis of Some Flexible Families of Distributions for Estimation of Wind Speed Distributions. Applied Energy, 89, 355-367. http://dx.doi.org/10.1016/j.apenergy.2011.07.045

[24] Mostafaeipour, A. (2010) Feasibility Study of Offshore Wind Turbine Installation in Iran Compared with the World. Renewable and Sustainable Energy Reviews, 14, 1722-1743. http://dx.doi.org/10.1016/j.rser.2010.03.032

[25] Wang, L., Yeh, T.H., Lee, W.J. and Chen, Z. (2011) Analysis of a Commercial Wind Farm in Taiwan, Part I: Measurement Results and Simulations. IEEE Transactions on Industry Applications, 47, 939-953. http://dx.doi.org/10.1109/TIA.2010.2101991

[26] Japan Meteorological Agency. http://www.jma.go.jp/jma/indexe.html

[27] AEOLOS Wind Turbine. http://www.windturbinestar.com/ 